\title{
Engineering Students and the Library - Forging That Critical First Link
}

\author{
Edwin M. Perry \\ University of Regina, Dr. John Archer Library \\ ed.perry@uregina.ca
}

\begin{abstract}
Engineering librarians occasionally experience difficulty getting an initial "in," that allimportant first connection with engineering students and faculty. In part, that may be because many do not have engineering degrees themselves. That said, a fundamental question arises- where and how can they make that initial contact? Equally important, how can the goals of the engineering faculty and the Library support one another? Engineering schools usually have a first year course intended to introduce broad aspects of the profession, and to show that Engineering does not exist in isolation. Rather, it interacts with and impacts upon society in a multitude of ways. The Canadian Engineering Accreditation Board mandates those same goals, and also requires that students learn to communicate adequately, both orally and in writing, and work effectively as part of a project team. The University of Regina Faculty of Engineering uses two first year classes to begin this process. It is at that point, in the first semester, that a connection between incoming students and the Library starts to be forged.
\end{abstract}

Index terms- Engineering undergraduate students, information literacy, library partnering.

\section{Introduction}

In the 1980s and 90s, numerous articles, surveys, and reports addressed a single question: were university graduates being properly prepared to enter the workforce and to meet the expectations of employers [1], [2]. In some cases, the question was asked by teaching faculty based on what they observed in the classroom and in papers written by their students. In others, the question originated with company CEOs and middle managers, expressing dissatisfaction over the capabilities of new employees. This was not a new topic - it was [and still is] discussed repeatedly at conferences and in the literature. Nor are the issues restricted to Engineering. They are common to many different professions. But the question became more sharply focused during this period. A broad consensus emerged about the core issues - ability to work as part of project teams, ability to do accurate, in-depth research, ability to communicate verbally and in writing, and an understanding of the ethical/social implications of their chosen professions In 1996, that resulted in a report, Engineering Criteria 2000, issued by the American Accreditation Board for Engineering and Technology, which led to substantially revised criteria for accrediting engineering programmes in the United States [3]. The technical knowledge of new graduates was often viewed as satisfactory to excellent. It was in the "softer" areas outlined above that problems were noted. A fourth general issue existed and continues to exist, discussed exhaustively within the library profession - a problem called "information overload."

Working as part of a team is essential. Projects now tend to be so complex and multi-faceted that a single person cannot operate in isolation. Clear, precise communication is necessary both inside the team, and with the client for whom a project is being conducted, with various planning and legislative bodies, and often with members of the general public [4]. Writing ability has always been crucial to communication, but never more so than now as face-to-face or telephone contact is replaced increasingly by email and mobile text messaging [5], [6]. Every employee needn't be Ernest Hemingway. But s/he shouldn't sound like James Joyce's Ulysses either. The following email message, quoted by Dillon in a 2004 New York Times report [7], illustrates a typical example of writing gone awry:

I updated the status report for the four discrepancies Lennie forward us via e-mail (they in Barry file)..to make sure my logic was correct It seems we provide Murray with incorrect information... However after verifying controls on JBL-JBL has the indicator as B???? - I wanted to make sure the recent changes-I processed todaybefore Murray make changes again on the mainframe ' $\mathrm{C}$ ' 
That sort of message does not constitute communication, and is becoming all too common. As Dillon indicates, e-mails such as the one above generate others [often just as obscurely worded] clogging up company computer systems with requests for clarification. Dillon also indicates that the cost to companies for remedial writing training of existing and new employees exceeds \$ 3 billion US per year. Yet that does not include the human cost for employees who are never hired, are dismissed, or cannot be promoted because of poor communication skills [8].

The problems of information overload and research skills are opposite sides of a single page. Never in human history has there been so much "information" available. In fact, the phrase "information explosion" was created in the 1970s to describe the massive increase in research papers and other documents. That in turn created "information overload," the necessity of sorting through multiple haystacks of documents to find the best information about a particular topic. Fortunately, we now have highly sophisticated electronic methods to do that sorting and to pinpoint the valuable material. The relatively small University of Regina Library has access to over 150 electronic indexing databases, covering literature in nearly every field. But these electronic search tools require training and practice to use effectively. They use a multitude of different interfaces, have varying system capabilities, and require sophisticated search techniques. Without training and experience, they are almost more frustrating than useful. Recent articles and studies are somewhat ambivalent as regards to whether progress is or is not being made on resolving many of the original problems [3], [4], [9]. It does appear that improvement still needs to occur, particularly in the areas of oral and written communication, teamwork, and management skills.

\section{Defining Criteria}

Canada is fortunate in having the Canadian Engineering Accreditation Board to assess university engineering programmes, and to establish national standards which those programmes must meet. Section 2.1 of the Board's "Accreditation Criteria and Procedures" [10] outlines the elements required in the curriculum; not merely technical knowledge, but communication skills, the ability to find and use appropriate information, the ability to function as an effective member of a team, and awareness of the role and responsibilities of the professional engineer in society. These mirror qualities about which faculty and employers have expressed concerns, past and present.

\section{Pursuing the Goals}

Our Faculty of Engineering makes an ongoing effort to develop teamwork, communication, and ethical/social consciousness in its students. The John Archer Library works in parallel with the Faculty to develop student skills in research, information retrieval and information management. Not merely because accreditation requires it, but because these qualities are essential to society and to the careers of our graduates. Other faculties in the University address many of the same issues, often during the second or third year of classes.

But at Regina, more than half the engineering students take the co-op option which includes work semesters. Within 18 months of entering university, they are out on their first placement, holding a salaried job in the real world, and expected to be productive. For that reason, the Faculty of Engineering works with a different timeframe. Each September, the 150-200 incoming students register for Engineering 103, The Impact of Technology on Society, a mandatory course. In one sense, this is similar to introductory courses offered by most schools of engineering. Students are told what will be expected of them by the University in general, and specifically by the Faculty of Engineering. Professors from each of our "systems" specialties make presentations outlining the goals of their programmes. Practicing engineers are invited as guest speakers to discuss the profession, and projects with which they are currently involved. However, the content and goals of this introductory class are considerably broader than that.

The students immediately divide into teams of six, and each selects a "team leader." Each group then picks a topic from a prepared list, or one of their own interest. These vary widely: non-nuclear weapons of mass destruction, rfid implanted chips, or the Avro Arrow project are typical examples. The students must then analyze their topic, and explore its technical, future, economic, social, political, and ethical aspects and implications. Each person is responsible for researching one or more parts. This is a situation where tools such as group instant messaging, or social software such as Second Life can be of significant use for coordination and problem-solving. Near the end of the semester, each team makes a joint oral presentation to the entire class, followed by a composite written report. The mark assigned for this team project constitutes $50 \%$ of the total grade for the class. Overall, it constitutes a complex and challenging assignment for students newly-graduated from secondary school.

In mid-September, the engineering librarian and two other members of the library staff deliver two hourlong instruction sessions for Engineering 103. The first 
is relatively general, introducing the library catalogue, the concept of Boolean logic as a search tool, and some quirks of the catalogue which can bite the innocent. With the help of documents on the library homepage, it also covers other ideas such as logging in from offcampus, evaluating internet material, the availability of over 150 indexing databases for specific subjects, and the interlibrary loan service. A second presentation, two days later, explores the research process. Using the Three Gorges Dam Project in China as a sample topic, it examines the same aspects the students will research in their own projects. This session begins with techniques for finding general background information using the library catalogue and an electronic encyclopaedia such as Answers.com. Then the Google Search engine is used to locate additional web-based material. In that regard, something is worth noting. A brief informal survey of a dozen incoming students in 2006 discovered that all twelve had used Google, and felt confident doing so. Three knew that Google had an "advanced search" method available and two had tried using it. None had even heard of the "scholar" option, which allows zeroing in on more scientific, academic, and reliable resources. The Three Gorges Dam example is an excellent one to demonstrate the value of "scholar." It reduces the initial retrieval of over 149,000 items down to approximately 368 . The results can then be further refined by adding more specific terms such as "social" or "environmental." Of those 368, a substantial number are reputable articles or reports. Two are called up "full text" during the class and examined.

The session moves forward, analyzing basic concepts in the project topic, listing synonyms to describe each concept, developing a focused "search strategy." Then that strategy is run on an actual database, ArticleFirst, to demonstrate how the amount of material retrieved can be reduced using several techniques, zeroing in on individual concepts. After a dozen highly relevant citations are selected, students learn how to open and manipulate actual articles if linked electronic versions exist. Some items are not linked electronically, or are not available in paper form in the University library. Students are shown how to locate those at other libraries using our GODOT search software, and how to request copies through our interlibrary loan service with two or three simple mouse clicks. By the end of the second session, the students are familiar with the three reference staff presenting the instructions, have names and contact information for them, and are encouraged to contact them directly, or to use the Archer Library's Information Desk when requiring assistance with their projects. Both the professor and the lab instructor direct students to the library staff on an ongoing basis throughout the semester. The reference staff has, on some occasions, worked directly with as many as 27 out of 33 project groups.

In the January semester, the same students register for another class, Engineering 113, Engineering Communications and Design. This course emphasizes communication ability and teamwork. Two major assignments continue the process begun in September. One is an analysis of an engineering catastrophe, done by students individually. A few incidents such as the Twin Towers Collapse or the Challenger Disaster are placed off-limits, because they have been examined so frequently and information is so readily located. Students must analyze the causes of the disaster, discern how the situation developed, and indicate where possible what changes in engineering design or other factors might have prevented or minimized the damage. This assignment emphasizes research techniques, analytical ability, problem solving, and the social responsibilities of professional engineers. The second assignment is a design project, again done by small groups of 5-6 students. In the winter 2007 semester, projects focused on designing various aids for the handicapped as outlined by the Tetra Society. These involved shopping baskets for wheelchairs, methods of supporting a trumpet for a one-armed musician, etc. Past groups have dealt with designs for portable basketball hoops, bottle crushers, and similar topics. These projects give students experience in actually designing an item to fulfil a useful purpose. Both written and oral presentation skills are stressed.

In January 2008, the engineering librarian will begin holding a session with Engineering 113 students to show them how to access a patents database, set up free accounts there, and perform searches to determine what designs relevant to their own projects have already been developed. Later that month, the librarian will meet again with the students to discuss the 1984 Gimli Glider Incident. In that event, an Air Canada jet ran out of fuel over the Ontario/Manitoba border, and made an emergency landing at the old Gimli airbase north of Winnipeg. The plane actually landed on a racetrack while cars were on the circuit, traveling at speeds up to $150 \mathrm{mph}$. The librarian is very familiar with the Gimli track, and has personal knowledge of the incident, including a number of factors never covered in the press reports. This session should give students some indication of what will be expected in their own catastrophe reports. A third library session may also be incorporated in 2008. That one, conducted by either the science or education librarian, would introduce students to the university's Refworks bibliographic software programme. Authors can import citations they are using for a paper or thesis into Refworks, then, with a few keystrokes, automatically rearrange them into whatever format is required - IEEE, MLA, APA, 
Council of Biological Editors, etc. That will become increasingly useful to students as they move into higher level classes, coop term reports, and graduate work.

Attention to developing research, writing and presentation skills is not restricted to these two classes. In early 2006, Engineering added a Technical Writer position to its staff. This position initially had two major roles. One was to assist faculty members and graduate students in preparing written materials, grant proposals, and to proof-read theses and article manuscripts. The other was to develop a series of workshops for students emphasizing technical writing techniques, avoidance of plagiarism, assessing information sources, performing literature reviews, and referencing source documents. These roles quickly expanded. The technical writer now also acts as a sessional lecturer, co-teaching Engineering 113, especially the communications and research techniques aspects of the course. Also on the Engineering side, a new programme at the graduate level, dealing with another increasingly important issue, engineering management skills, is in the advanced development phase. Further instruction sessions with faculty, graduates, and fourth year students are currently being planned by the library for 2007/08. These will cover topics such as the Refworks bibliographic software, and accessing patent information. In September, a "chat reference" service will be initiated, permitting immediate electronic interaction between clients and reference staff. That change should prove especially useful to students in the co-op programme while they are on work terms remote from the University campus.

\section{Conclusions}

Clearly, the University of Regina's Faculty of Engineering makes determined efforts to address problem areas outlined at the opening of this paper. The John Archer Library shares, and works in parallel toward, many of the same goals. Initial contact with new engineering students is established during two mandatory first year classes. Information provided in library instruction sessions is of clear and immediate use for major assignments. "Face recognition," and the assistance provided for beginning students, establishes a base on which to build closer ties during higher level classes, design projects, co-op work semesters, and graduate work. Library involvement in support of faculty research projects is also increasing. Active cooperation at many levels between the Faculty of Engineering and the Library already exists. The goal now is to further strengthen and build upon that foundation.

\section{Acknowledgement}

The author wishes to acknowledge the assistance of Dr. David de Montigny, and Heidi Smithson, University of Regina Faculty of Engineering, who provided input. Also thanks to Loretta Gustafson, Archer Library Systems Office, who formatted the final document.

\section{References}

[1] S. Katz, “The Entry-Level Engineer: Problems in Transition from Student to Professional," Journal of Engineering Education, vol. 82, no.3, pp. 171-174, July 1993.

[2] K. Black, "An Industry View of Engineering Education,” Journal of Engineering Education, vol. 83, no.1, pp. 26-28, Jan. 1994.

[3] A. Brown, "Engineers Well Prepared," Mechanical Engineering, vol. 128, no. 8, pp. 10-11, Aug. 2006.

[4] E. Vance, "College Graduates Lack Key Skills, Report Says," The Chronicle of Higher Education, vol. 53, no. 22, p. A30, Feb 22007.

[5] P. Jacobs, "Strong Writing Skills Essential for Success, Even in IT,” InfoWorld, vol. 20, no. 27, p.86, Jul 6 1998.

[6] B. Stevens, "What Communication Skills Do Employers Want? Silicon valley Recruiters Respond,” Journal of Employment Counseling, vol. 42, no. 1, pp. 2-8, Mar 2005.

[7] S. Dillon, "What Corporate America Can’t Build: a Sentence,” New York Times, p. 23, col. 1, Dec 7, 2004.

[8] G. Budig, "Writing: a Necessary Tool: Mr. Budig Issues a Call to Policy Makers, Educators, and Business Leaders to Get Serious About Improving Our Students' Writing Skills,” Phi Delta Kappan, vol. 87, no. 9, p. 663, May 2006.

[9] E. Koehn, "Assessment of Communications and Collaborative Learning in Civil Engineering Education," Journal of Professional Issues in Engineering Education and Practice, vol. 127, no. 4, p. 160, Oct. 2001.

[10] Canadian Engineering Accreditation Board, Accreditation Criteria and Procedures, Canadian Council of Professional Engineers, Ottawa, 2006. 